\section{A) Check for updates}

Cite this: Inorg. Chem. Front., 2020, 7, 631

Received 4th September 2019, Accepted 22nd November 2019 DOI: 10.1039/c9qi01140d

rsc.li/frontiers-inorganic

\title{
Stable surface functionalization of carbonized mesoporous silicon $\dagger$
}

\author{
Joakim Riikonen, (D) a,b,c Tuomo Nissinen, ${ }^{a}$ Aino Alanne, ${ }^{d}$ Rinez Thapa, ${ }^{a}$ \\ Philippe Fioux, b,c Magali Bonne, (D) b,c Séverinne Rigolet, (iD b,c \\ Fabrice Morlet-Savary, ${ }^{b, c}$ Fabien Aussenac, ${ }^{e}$ Claire Marichal, b,c Jacques Lalevée, (ID b,c \\ Jouko Vepsäläinen, ${ }^{d}$ Bénédicte Lebeau (D) b,c and Vesa-Pekka Lehto (D) *a
}

\begin{abstract}
Mesoporous silicon (PSi) is an emerging nanomaterial studied in e.g. biomedical, sensor and energy applications. In many applications, a major obstacle in its commercial use is the instability of its surfaces, especially when functionalized with organic molecules. In the present work, we introduce a surface functionalization method for PSi, in which carbonized surface of silicon is functionalized with terminal alkenes. A good surface coverage of 0.3 molecules per $\mathrm{nm}^{2}$ was achieved and the material showed excellent aqueous stability at low and neutral $\mathrm{pH}$. It also withstood a highly basic solution for several days. The developed method was used to graft bisphosphonates on the surface and the material was used for metal adsorption. Because of its excellent stability, the adsorbent material lasted up to 50 adsorption/desorption cycles without a significant deterioration of its performance.
\end{abstract}

\section{Introduction}

Mesoporous silicon (PSi) has many potential applications in e.g. drug delivery, sensing, Li-ion batteries and adsorption. It is relatively unstable in its native form because of its high surface area and reactivity of the $\mathrm{Si}-\mathrm{Si}$ bonds. Therefore, surface of PSi is typically passivated by oxidation, carbonization or hydrosilylation to improve its stability.

Many applications of PSi, such as sensing and separation, require grafting of functional molecules on the surface. ${ }^{1,2}$ The stability of these surfaces has been a focus of several studies. $^{2-6}$ Among the first functionalization strategies of PSi was grafting of alkenes, or alkynes on PSi by hydrosilylation. ${ }^{7}$ Although the highly hydrophobic surfaces passivated by hydrosilylation are shown to be stable for several hours even at $\mathrm{pH}$ $13,^{8}$ the grafting of molecules with functional groups, such as carboxylic acids, leads to significantly less stable materials. ${ }^{6}$ Good to moderate stability of the hydrosilylated materials in aqueous solutions near neutral $\mathrm{pH}$ has been shown only up to

\footnotetext{
${ }^{a}$ Department of Applied Physics, University of Eastern Finland, Yliopistonranta $1 \mathrm{~F}$, 70211 Kuopio, Finland. E-mail: vesa-pekka.lehto@uef.fi

${ }^{b}$ Université de Haute Alsace, CNRS, IS2M UMR 7361, F-68100 Mulhouse, France

${ }^{c}$ Université de Strasbourg, France

${ }^{d}$ School of Pharmacy, University of Eastern Finland, Yliopistonranta 1B, 70211 Kuopio, Finland

${ }^{e}$ Bruker Biospin SA, 34, rue de l'industrie, 67166 Wissembourg Cedex, France $\dagger$ Electronic supplementary information (ESI) available. See DOI: 10.1039/ c9qi01140d
}

few hours ${ }^{3,9}$ with the exception of a 2-month stability study conducted by Kilian et al. ${ }^{5}$ They observed dissolution of PSi in phosphate buffered saline visually after one month but also saw significant changes in the structure in the first few days. However, the amount of the grafted molecules on the surface was not studied directly.

Many surface functionalization strategies rely on grafting organic molecules on oxidized PSi via $\mathrm{Si}-\mathrm{O}$ bonds which are easily hydrolyzed in an aqueous environment and are thus sensitive to degradation. ${ }^{10} \mathrm{~A}$ more stable functionalization can be achieved if only stable $\mathrm{Si}-\mathrm{C}$ and $\mathrm{C}-\mathrm{C}$ bonds are exposed on the surface. Sciacca et al. and Jalkanen et al. studied hydrophobic PSi that was thermally hydrocarbonized at $500{ }^{\circ} \mathrm{C}$ and subsequently functionalized with a carboxylic acid. ${ }^{4,6}$ Sciacca et al. observed an improved structural stability of the material in phosphate buffered saline for $2 \mathrm{~h}$. Jalkanen et al. studied the stability in harsher conditions and observed complete dissolution of the material in $1 \mathrm{M} \mathrm{KOH}$ in $24 \mathrm{~h}$.

Thermal carbonization of PSi at high temperatures (above $800^{\circ} \mathrm{C}$ ) has been shown to produce highly stable surfaces consisting of silicon carbide, silicon oxycarbide and carbon. ${ }^{11,12}$ So far, functionalization of thermally carbonized PSi (TCPSi) has been performed via silanization which grafts functional molecules on the surface via $\mathrm{Si}-\mathrm{O}$ bonds leaving the functional molecules susceptible to hydrolysis. ${ }^{13}$

In the present study, a new functionalization method for TCPSi is introduced in which terminal alkenes are directly grafted on the carbonized silicon surface leading to functionalization which is highly stable in aqueous solutions 
for several weeks and resists even high pH solutions for several days.

The developed method is used to functionalize TCPSi with bisphosphonates that are good chelation agents for metals. ${ }^{14}$ Several mesoporous materials have been proposed for metal adsorption applications ${ }^{15-20}$ but their repeated use has often not been studied supposedly due to their low stability and diminishing performance. If repeated use is studied, it is reported for less than ten ad/desorption cycles and even the most stable materials lose at least $1 \%$ of their capacity per cycle. ${ }^{15-17}$ The aim of the present study is to provide a material that can be reused several tens of times without significant reduction of its capacity thus essentially reducing the costs in demanding applications.

\section{Experimental}

\subsection{Production of PSi}

PSi was produced by electrochemical etching in 1:1 $\mathrm{HF}$ (38-40\%)/EtOH mixture on $\mathrm{p}+$ Si wafers $(0.01-0.02 \Omega \mathrm{cm})$ with $40 \mathrm{~mA} \mathrm{~cm}{ }^{-2}$ current density for $2400 \mathrm{~s}$. HF is highly toxic and a special care should be taken to prevent any contact with the liquid and inhalation of vapor. PSi films were detached from the wafer with a high current pulse and dried at $65{ }^{\circ} \mathrm{C}$ for $2 \mathrm{~h}$. The PSi films were milled to microparticles in a planetary ball mill and sieved to $25 \mu \mathrm{m}-75 \mu \mathrm{m}$ size fraction. PSi was used in different forms, microparticles, freestanding films or films supported on the substrate depending on the demands of measurement in order to obtain high quality data. Films supported on the substrate were produced similarly as above by etching a $5 \mu \mathrm{m}$ porous layer on the wafer without the high current pulse.

\subsection{Bisphosphonate synthesis}

10-Undecenoic acid, oxalyl chloride and $\mathrm{P}\left(\mathrm{OSiMe}_{3}\right)_{3}$ were purchased from Aldrich. $\mathrm{CDCl}_{3}$ (D 99.96\%) used as NMR solvent was purchased from Euriso-Top.

The bisphosphonate molecule (Tetrakis(trimethylsilyl) 1-(trimethylsilyloxy)undec-10-ene-1,1-diylbisphosphonate) was synthesized according to the method published by Lecouvey et al. (ESI Fig. S1†). ${ }^{21}$ 10-undecenoic acid (13.56 mmol, $2.50 \mathrm{~g}$ ) in $20 \mathrm{ml}$ of freshly distilled dichloromethane was placed in dried two necked flask equipped with an argon inlet. Oxalyl chloride (27.10 mmol, $3.44 \mathrm{~g}$ ) was added dropwise on ice. The reaction mixture was stirred at room temperature for 1 hour, evaporated and the formation of the corresponding acid chloride was observed by NMR. Two equivalents of tris(trimethyl silyl) phosphite $(27.10 \mathrm{mmol}, 8.09 \mathrm{~g})$ was added dropwise to the acid chloride under argon at $0{ }^{\circ} \mathrm{C}$. Once the addition was complete, the reaction mixture was left under magnetic stirring at room temperature for $2 \mathrm{~h}$. Volatile fractions were then evaporated under reduced pressure. Yellow oily substance with $94 \%$ yield was obtained. ${ }^{1} \mathrm{H}$ NMR $\left(500.1 \mathrm{MHz}, \mathrm{CDCl}_{3}\right) \delta 5.80$ (ddt, $1 \mathrm{H}$, ${ }^{3} J_{\mathrm{HH}}=17.2,10.3$ and $6.7 \mathrm{~Hz}, \mathrm{CH}_{2}=\mathrm{CH}-\mathrm{CH}_{2}$ ), $4.98(\mathrm{dd}, 1 \mathrm{H}$, $\left.{ }^{3} J_{\mathrm{HH}}=17.2,{ }^{2} J_{\mathrm{HH}}=2.2, \mathrm{CH}_{2}=\mathrm{CH}\right), 4.92\left(\mathrm{~d}, 1 \mathrm{H},{ }^{3} J_{\mathrm{HH}}=10.3\right.$, $\left.{ }^{2} J_{\mathrm{HH}}=2.2, \mathrm{CH}_{2}=\mathrm{CH}\right), 2.07-1.99(\mathrm{~m}, 2 \mathrm{H}), 1.96-1.84(\mathrm{~m}, 2 \mathrm{H})$, 1.60-1.51 (m, 2H), 1.41-1.33 (m, 2H), 1.33-1.20 (m, 8H), 0.34-0.25 (m, 45H); ${ }^{13} \mathrm{C}$ NMR (125.8 MHz, $\left.\mathrm{CDCl}_{3}\right) \delta$ 139.0, 114.1, $78.2\left(\mathrm{t},{ }^{1} J_{\mathrm{CP}}=166.2 \mathrm{~Hz}\right), 35.6,33.7,30.3,29.4,29.4,29.0$, 28.9, $23.8\left(\mathrm{t},{ }^{2} J_{\mathrm{CP}}=6.5 \mathrm{~Hz}\right), 2.8$ (3C), $1.4(6 \mathrm{C}), 1.3(6 \mathrm{C}) ;{ }^{31} \mathrm{P}$ NMR $\left(202.5 \mathrm{MHz}, \mathrm{CDCl}_{3}\right) \delta 1.95(\mathrm{~s})$. The compound was left in silylated form to achieve good solubility in mesitylene.

\subsection{Surface modifications}

Three independent surface modifications were performed for each sample type. First, hydrogen terminated PSi (HTPSi) was prepared by briefly immersing PSi in $1: 1 \mathrm{HF} / \mathrm{EtOH}$ mixture and drying at $65^{\circ} \mathrm{C}$ for $2 \mathrm{~h}$.

The carbonization was performed to the HTPSi in a quartz tube under continuous $\mathrm{N}_{2}$ flow of $1 \mathrm{~L} \mathrm{~min}^{-1}$ throughout the process. Samples were first flushed with nitrogen for $30 \mathrm{~min}$ then acetylene flow of $1 \mathrm{~L} \mathrm{~min}{ }^{-1}$ was added for $15 \mathrm{~min}$. The sample was then placed into a preheated oven at $500{ }^{\circ} \mathrm{C}$. After $15 \mathrm{~min}$ at $500{ }^{\circ} \mathrm{C}$, the acetylene flow was terminated and the tube was removed from the oven and sample were let to cool down to room temperature (in nitrogen flow). At room temperature, acetylene flow $\left(1 \mathrm{~L} \mathrm{~min}^{-1}\right)$ was applied again for $9 \mathrm{~min}$ $40 \mathrm{~s}$ and the sample was inserted into the oven at $820^{\circ} \mathrm{C} 20 \mathrm{~s}$ after the acetylene flow was terminated. Sample was heated in the oven for $10 \mathrm{~min}$ and then cooled down to room temperature (in nitrogen flow).

For surface functionalization of TCPSi, the neat alkene (undecylenic acid or decene) was added on the TCPSi in the quartz tube and the tube was heated at $120{ }^{\circ} \mathrm{C}$ for $16 \mathrm{~h}$. Bisphosphonate functionalization was performed with a mesitylene solution $^{22}$ of $\mathrm{BP}$ ( $9 \mathrm{wt} \%, 1$ : 1 mass ratio of $\mathrm{BP}$ and PSi). The undecylenic acid grafted TCPSi is labeled UnTCPSi, the decene grafted TCPSi DeTCPSi and the bisphosphonate grafted TCPSi BPTCPSi. The structures of all the PSi materials used in the study are presented in ESI Fig. S2. $\dagger$ The UnTCPSi samples were rinsed thrice with $25 \mathrm{ml}$ chloroform to remove excess undecylenic acid and then six times with $25 \mathrm{ml}$ of a 1:1 mixture of EtOH and $1 \mathrm{M} \mathrm{NaOH}$ in order to remove physisorbed or dimerized undecylenic acid. The particles were then washed with water and $1 \mathrm{M} \mathrm{HCl}$ to convert grafted undecylenic acid from $\mathrm{Na}$ salt to the acid form and finally rinsed with water to remove $\mathrm{HCl}$ and dried at $65{ }^{\circ} \mathrm{C}$. DeTCPSi was washed eight times with $25 \mathrm{ml}$ of chloroform and dried at $65^{\circ} \mathrm{C}$ for $1 \mathrm{~h}$. BPTCPSi was washed eight times with $25 \mathrm{ml}$ of chloroform, then with methanol and dried at $65{ }^{\circ} \mathrm{C}$ for $1 \mathrm{~h}$.

To prepare undecylenic acid grafted HTPSi (UnHTPSi), HTPSi was immersed in neat undecylenic acid and heated at $120{ }^{\circ} \mathrm{C}$ for $16 \mathrm{~h}$. The material was washed eight times with $25 \mathrm{ml}$ of chloroform and dried at $65^{\circ} \mathrm{C}$ for $1 \mathrm{~h}$.

\subsection{Liquid NMR}

${ }^{1} \mathrm{H},{ }^{31} \mathrm{P}$ and ${ }^{13} \mathrm{C}$ NMR spectra were measured on a Bruker Avance 500 DRX spectrometer operating at 500.1, 202.5 and 125.8 $\mathrm{MHz}$, respectively. The NMR spectra measured in $\mathrm{CDCl}_{3}$ were calibrated on the solvent residual signals at $7.26 \mathrm{ppm}$ for 
${ }^{1} \mathrm{H}$ and $77.1 \mathrm{ppm}$ for ${ }^{13} \mathrm{C}$ and $85 \% \mathrm{H}_{3} \mathrm{PO}_{4}$ was used as an external standard in the ${ }^{31} \mathrm{P}$ measurements.

\subsection{Nitrogen sorption}

Prior to the measurements, the samples were degassed in vacuum at $65{ }^{\circ} \mathrm{C}$ for $2 \mathrm{~h}$. The nitrogen adsorption and desorption isotherms were measured with Micromeritics Tristar II 3020. Surface area was calculated using BET (Brunauer, Emmett and Teller) theory, pore size distributions were calculated with $\mathrm{BJH}$ (Barrett, Joyner and Halenda) theory and pore volume was calculated from a single point at relative pressure of 0.95 .

\subsection{Electron paramagnetic resonance (EPR)}

TCPSi microparticles which were not exposed to air were transferred under nitrogen atmosphere into a glove box with $\mathrm{Ar}$ atmosphere. In the glove box, the sample was transferred into $6 \mathrm{~mm}$ cylindrical quartz tubes and closed. Electron paramagnetic resonance experiments were performed using an X-Band spectrometer (Bruker EMX-plus Biospin). The radicals were observed under Ar atmosphere at room temperature. The experimental procedure has previously been described in detail. $^{23}$ The double integral of the EPR spectrum is proportional to the concentration of paramagnetic centers. A calibration was first done using TEMPO to ensure that this procedure was usable in solid state. TEMPO was also used as standard for calibration of the $g$-factor $(g=2.0061)$. To measure change in paramagnetic species caused by addition of undecylenic acid on the TCPSi particles that had not been exposed to air, undecylenic acid was injected into the quartz tube and the EPR spectrum was measured immediately. In addition to the above measurements TCPSi that had been in contact with air was measured in air atmosphere.

\subsection{Solid state NMR characterization}

${ }^{1} \mathrm{H}^{-29} \mathrm{Si}$ CPMAS NMR experiments were performed at room temperature, with a Bruker Avance II 300 spectrometer operating at $B_{0}=7.1 \mathrm{~T}$ (Larmor frequency: $\omega_{0}{ }^{29} \mathrm{Si}$ ) $=59.61 \mathrm{MHz}$ and $\omega_{0}\left({ }^{1} \mathrm{H}\right)=300.08 \mathrm{MHz}$ ) with a Bruker double channel $7 \mathrm{~mm}$ probe at a spinning frequency of $4 \mathrm{kHz}$, with a proton $\pi / 2$ pulse duration of $4.1 \mu \mathrm{s}$, a contact time of $4 \mathrm{~ms}$ and a recycle delay of $5 \mathrm{~s}$ according to $T 1$ measurements. ${ }^{29} \mathrm{Si}$ Chemical shifts were referenced to tetramethylsilane (TMS).

${ }^{31} \mathrm{P}$ solid-state MAS NMR experiments were performed at room temperature on Bruker Avance II 400 spectrometer operating at $B_{0}=9.4 \mathrm{~T}$ equipped with a Bruker double channel $4 \mathrm{~mm}$ probe at a Larmor frequency of $161.99 \mathrm{MHz}$. The spectrum was recorded with a $\pi / 2$ pulse duration of $3 \mu$ s and a recycling delay of $5 \mathrm{~s}$ at a spinning frequency of $12 \mathrm{kHz} .{ }^{31} \mathrm{P}$ spin lattice relaxation times $\left(T_{1}\right)$ were measured with the saturationrecovery pulse sequence. ${ }^{31} \mathrm{P}$ spectrum was referenced to $\mathrm{H}_{3} \mathrm{PO}_{4}$ (85\% in water).

\subsection{DNP NMR characterization}

Solid State DNP experiments were performed with a Bruker $263 \mathrm{GHz}$ Solid-State NMR DNP spectrometer with a gyrotron microwave source, ${ }^{24,25}$ Ascend DNP 400 WB NMR magnet,
Avance III NMR console and a low-temperature $3.2 \mathrm{~mm}$ triple resonance ${ }^{1} \mathrm{H} / \mathrm{X} / \mathrm{Y}$ DNP MAS probe. The NMR $400 \mathrm{MHz}$ Ascend DNP magnet is equipped with a sweep coil for optimization of the frequency match between the NMR and the electron frequencies. The sample temperature reported was $108 \mathrm{~K}$ with microwave irradiation. The microwave power was optimized to achieve the highest DNP signal enhancement. ${ }^{1} \mathrm{H}-{ }^{13} \mathrm{C}$ cross polarization (CP) MAS experiments were performed with Spinal64 ${ }^{26}{ }^{1} \mathrm{H}$ decoupling during acquisition time. During the CP contact time, both ${ }^{1} \mathrm{H}$ and ${ }^{13} \mathrm{C}$ R.F. field were set to $60 \mathrm{kHz}$, the ${ }^{1} \mathrm{H}$ decoupling R.F. field strength was set to $95 \mathrm{kHz}$ during the acquisition time. The contact time during the CP step was set to $1 \mathrm{~ms}$. The sample spinning frequency was set to $12 \mathrm{kHz}$. 8192 scans were acquired with a recycle delay of $6 \mathrm{~s}$ which corresponds to a total acquisition time of about $13.5 \mathrm{~h}$.

DNP polarization buildup time (TDNP) measurements were performed using saturation-recovery experiments and results were fit in the $\mathrm{T} 1 / \mathrm{T} 2$ relaxation module of Topspin software.

Approximately $10 \mathrm{mg}$ of TCPSi microparticles were loaded in a $3.2 \mathrm{~mm}$ sapphire rotor. The rotor was sealed with a Teflon top insert and a Zirconia cap. Chemical shifts were referenced to tetramethylsilane (TMS).

\subsection{XPS analysis}

X-ray photoelectron spectroscopy (XPS) spectra were recorded with a VG SCIENTA SES-2002 spectrometer equipped with a concentric hemispherical analyzer. The incident radiation used was generated by a monochromatic $\mathrm{Al} \mathrm{K \alpha} \mathrm{X}$-ray source (1486.6 eV) operating at $420 \mathrm{~W}(14 \mathrm{kV} ; 30 \mathrm{~mA})$. Photo-emitted electrons were collected at a take-off angle of $90^{\circ}$ from the surface substrate, with electron detection in the constant analyser energy mode (FAT). Widescan spectrum signal was recorded with a pass energy of $500 \mathrm{eV}$ and for high resolution spectra (Si 2p, C 1s and Cu 2p) pass energy was set to $100 \mathrm{eV}$. Approximately $24 \mathrm{~mm}^{2}$ area of TCPSi film on Si substrate was analysed. The base pressure in the analysis chamber during experimentation was $\mathrm{ca} \cdot 10^{-9} \mathrm{mbar}$. The spectrometer energy scale was calibrated using the $\mathrm{Ag} 3 \mathrm{~d}^{5 / 2}$, Au $4 \mathrm{f}^{7 / 2}$ and $\mathrm{Cu} 2 \mathrm{p}^{3 / 2}$ core level peaks, set respectively at binding energies of 368.2, 84.0 and $932.6 \mathrm{eV}$. Spectra were subjected to a Shirley baseline and peak fitting was made with mixed Gaussian-Lorentzian components with equal full-width-at-half-maximum (FWHM) using CASAXPS version 2.3.17 software. The surface composition expressed in atom\% was determined using integrated peak areas of each component and take into account transmission factor of the spectrometer, mean free path and Scofield sensitivity factors of each atom. All the binding energies (BE) are referenced to the $\mathrm{C} 1 \mathrm{~s}$ peak at $284.5 \mathrm{eV}$ and given with a precision of $0.1 \mathrm{eV}$. The measured samples were porous films on silicon substrate except for the BPTCPSi samples which were measured as microparticles.

\subsection{FTIR analysis}

FTIR measurements were done in transmission mode with freestanding PSi films with Thermo Scientific Nicolet 8700 . The spectral range was $500-4000 \mathrm{~cm}^{-1}$ and resolution $4 \mathrm{~cm}^{-1}$. 


\subsection{Thermogravimetry}

Microparticles were measured by TA TGA Q50 under nitrogen atmosphere. The samples were equilibrated at $80{ }^{\circ} \mathrm{C}$ for $30 \mathrm{~min}$ and then heated up to $700{ }^{\circ} \mathrm{C}$ with $20{ }^{\circ} \mathrm{C} \mathrm{min}^{-1}$ heating rate.

\subsection{Scanning electron microscopy}

Zeiss HD|VP HR-SEM was utilized for investigation of the morphologies of the particles. The particles were attached to standard aluminum SEM sample holders with conductive carbon adhesive. The imaging was performed with acceleration voltage of $5 \mathrm{kV}$ and InLens detector.

\subsection{Stability study}

One hundred $\mathrm{mg}$ of UnHTPSi and UnTCPSi microparticles were first wetted with $\mathrm{EtOH}$ and then immersed in $45 \mathrm{ml}$ of 1 $\mathrm{M} \mathrm{HCl}$, deionized water or $1 \mathrm{M} \mathrm{NaOH}$. The samples were kept at $30{ }^{\circ} \mathrm{C}$. Part of the samples were removed at predefined time points and washed on a filter paper $3 \times$ with $50 \mathrm{ml}$ of deionized water, $3 \times$ with $50 \mathrm{ml}$ of $1: 1$ mixture of deionized water and ethanol and $4 \times$ with $50 \mathrm{ml}$ of EtOH. The particles were then dried at $65^{\circ} \mathrm{C}$. At each time point the liquid in which the particles were immersed was replaced with a fresh one.

\subsection{Metal adsorption}

Metal adsorption capacity towards copper was investigated using $200 \mathrm{mg}$ BPTCPSi particles primed in $20 \mathrm{ml}$ of $5 \mathrm{M} \mathrm{HCl}$ for $1 \mathrm{~h}$ at RT. After washing thrice with $20 \mathrm{ml}$ water, the particles were immersed in $20 \mathrm{ml}$ of $200 \mathrm{ppm} \mathrm{Cu}^{2+}$ solution (from $\left.\mathrm{CuCl}_{2}\right)$ at $\mathrm{pH}=4.02$ with constant mixing. The contact time was $24 \mathrm{~h}$ at RT. Cu concentration of the solution was measured before and after adsorption using total reflection X-ray fluorescence spectroscopy, tXRF (S2 Picofox, Bruker). The adsorbed amount was calculated from the concentration difference of the solutions. The reusability of the material was studied by repeating 50 adsorption/desorption cycles. $50 \mathrm{mg}$ of BP-TCPSi particles were placed inside a syringe filter and the following solutions were passed through the particles by gravitation in each cycle: $5 \mathrm{ml}$ of $10 \mathrm{ppm} \mathrm{Cu}^{2+}, 5 \mathrm{ml}$ of deionized $\mathrm{H}_{2} \mathrm{O}, 5 \mathrm{ml}$ of $0.1 \mathrm{M} \mathrm{HCL}$ and $5 \mathrm{ml}$ of deionized $\mathrm{H}_{2} \mathrm{O}$. Cu concentrations of the solution before and after each cycle was measured with PerkinElmer 5100 flame atomic absorption spectrometer (AAS) with a wavelength of $327.4 \mathrm{~nm}$ to calculate the adsorbed/desorbed amounts of $\mathrm{Cu}$.

\section{Results and discussion}

Thermal carbonization of PSi was performed under nitrogen atmosphere with acetylene gas in a two-step process at 500 and $820{ }^{\circ} \mathrm{C} .{ }^{11}$ After carbonization, the material is cooled to room temperature in nitrogen gas. According to a previous observation, the material will react strongly with a sudden exposure to air and emit bright light (see video in ESI $\dagger$ ). A TCPSi sample, that had not been exposed to air, was measured with EPR and observed a high number of carbon radicals in the material $\left(3.4 \times 10^{18} \mathrm{~g}^{-1}\right)$. We hypothesized that these radical groups could be utilized to functionalize the material by free radical addition. Therefore, undecylenic acid or 1-decene was added on the TCPSi immediately after carbonization before exposing the material to air. The mixture was then heated at $120{ }^{\circ} \mathrm{C}$ for $16 \mathrm{~h}$ to further enhance the grafting. The undecylenic acid and 1-decene modified TCPSi samples are referred to as UnTCPSi and DeTCPSi, respectively. Bisphosphonate (BP) grafted TCPSi (BPTCPSi) was also prepared in a similar way for metal adsorption experiments (see Materials and methods for details). A reference sample was prepared by grafting undecylenic acid on hydrogen terminated PSi (UnHTPSi) using conventional hydrosilylation by immersing hydrogen terminated PSi (HTPSi) in undecylenic acid at $120{ }^{\circ} \mathrm{C}$ for $16 \mathrm{~h}$. All the surface functionalizations were performed in triplicates to assess repeatability of the method.

The amount of grafted molecules on the samples, measured by thermogravimetry (TG), was $2.3 \pm 0.3 \mathrm{wt} \%$ in UnTCPSi, $4.6 \pm$ $0.3 \mathrm{wt} \%$ in DeTCPSi and $2.7 \pm 0.8 \mathrm{wt} \%$ in UnHTPSi corresponding to grafting densities of $0.3,0.9$ and 0.4 molecules per $\mathrm{nm}^{2}$, respectively (Table 1). Analysis of UnHTPSi was difficult because mass increase was taking place during the measurement presumably because of oxidation of the material by residual oxygen in the instrument. Very little mass loss was observed in UnTCPSi under $350{ }^{\circ} \mathrm{C}$ proving that undecylenic acid was covalently grafted on the surface whereas in DeTCPSi mass loss begun already at $200{ }^{\circ} \mathrm{C}$ indicating that some physisorbed molecules were also present (Fig. 1). A control sample

Table 1 Mass of the organic layer on the materials and the results of nitrogen sorption experiments

\begin{tabular}{|c|c|c|c|c|c|c|}
\hline & $A^{a}\left(\mathrm{~m}^{2} \mathrm{~g}^{-1}\right)$ & $C_{\mathrm{BET}}^{b}$ & $V^{c}\left(\mathrm{~cm}^{3} \mathrm{~g}^{-1}\right)$ & $D^{d}(\mathrm{~nm})$ & $m^{e}(\%)$ & Coverage $^{f}\left(\mathrm{~nm}^{-2}\right)$ \\
\hline HTPSi & $242 \pm 1$ & $28.8 \pm 0.3$ & $1.33 \pm 0.01$ & $17.0 \pm 0.1$ & - & - \\
\hline UnHTPSi & $211 \pm 7$ & $35.0 \pm 0.4$ & $0.94 \pm 0.08$ & $15.2 \pm 0.2$ & $2.7 \pm 0.8$ & $0.4 \pm 0.2$ \\
\hline TCPSi & $240 \pm 5$ & $73.9 \pm 0.6$ & $0.98 \pm 0.02$ & $15.8 \pm 0.1$ & - & - \\
\hline UnTCPSi & $223 \pm 4$ & $57 \pm 6$ & $0.91 \pm 0.01$ & $15.6 \pm 0.2$ & $2.3 \pm 0.3$ & $0.34 \pm 0.04$ \\
\hline DeTCPSi & $220 \pm 20$ & $35 \pm 3$ & $0.9 \pm 0.1$ & $15.2 \pm 0.5$ & $4.7 \pm 0.3$ & $0.90 \pm 0.08$ \\
\hline BPTCPSi & $224 \pm 2$ & $50 \pm 1$ & $0.87 \pm 0.01$ & $14.5 \pm 0.6$ & $2.9 \pm 0.5$ & $0.23 \pm 0.04$ \\
\hline
\end{tabular}

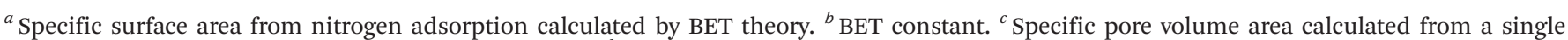

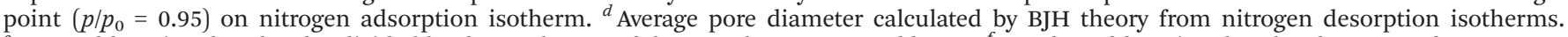
${ }^{e}$ Mass of functional molecules divided by the total mass of the sample as measured by TG. ${ }^{f}$ Number of functional molecules per surface area. 


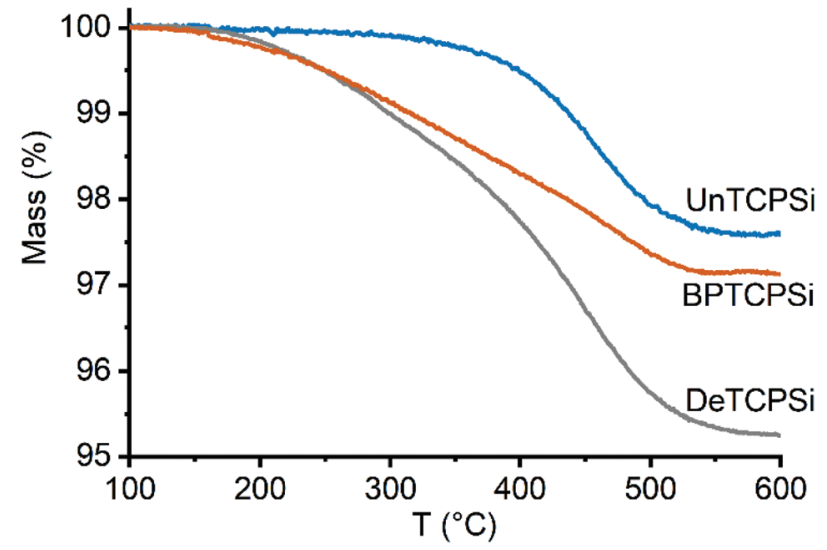

Fig. 1 TG curves of functionalized TCPSi samples showing mass loss due to decomposition of the functional layer.

was also prepared by exposing a TCPSi sample to air after the carbonization and subsequently immersing it in undecylenic acid at $120^{\circ} \mathrm{C}$ for $16 \mathrm{~h}$. In this sample, a significant amount of undecylenic acid was grafted on the TCPSi surface but the mass of the organic layer was $46 \%$ smaller than in the sample not exposed to air before functionalization.

The effect of surface functionalization on the pore structure was measured by nitrogen sorption. The surface area, BET constant, pore volume and average pore diameter for HTPSi and TCPSi samples before and after functionalization are shown in Table 1 and the isotherms are shown in ESI S3. $\dagger$ Functionalization caused a decrease in surface area, pore volume and average pore diameter. These values decreased between 10 and $30 \%$ after functionalization of HTPSi and between 1 and $12 \%$ after functionalization of TCPSi showing that the new functionalization method did not affect the pore structure substantially. Functionalization also affected the BET constant $\left(C_{\mathrm{BET}}\right)$ of the materials. HTPSi had a small $C_{\mathrm{BET}}$ value of 28.8 that increased to 34.4 after the functionalization with undecylenic acid. The opposite is observed with TCPSi that had a relatively high $C_{\mathrm{BET}}$ of 73.9. After the functionalizations with undecylenic acid or decene, the $C_{\mathrm{BET}}$ decreased to 57 and 35 , respectively, indicating that the functionalized surface had weaker interactions with the $\mathrm{N}_{2}$ molecule than the non-functionalized surface.

The materials were characterized by X-ray photoelectron spectroscopy (XPS), Fourier transform infrared spectroscopy (FTIR), ${ }^{29} \mathrm{Si}$ cross polarization magic angle spinning nuclear magnetic resonance spectroscopy (CP-MAS NMR) and ${ }^{13} \mathrm{C}$ CPMAS dynamic nuclear polarization (DNP) NMR in order to characterize the chemical groups present on the materials. According to XPS, the samples consisted of $\mathrm{Si}, \mathrm{C}, \mathrm{O}$ and trace level impurities of $\mathrm{Na}$ and $\mathrm{F}$ (Table 2). As reported earlier, TCPSi consisted mainly of silicon, graphitic carbon, SiC and silicon oxycarbides. ${ }^{12}$ No silicon dioxide was detected. An increased amount of $\mathrm{COOH}$ was detected for undecylenic acid functionalized samples, UnHTPSi containing more $\mathrm{COOH}$ compared with UnTCPSi. It is worth noting that three measurements were performed on each sample revealing a good reproducibility for the TCPSi samples whereas it is not the case for the HTPSi samples indicating higher instability and/or heterogeneity. Relatively high carbon content from 21 to 65 atomic \% was due to the surface sensitive nature of the measurements and impurities adsorbed from the air and does not reflect accurately the overall carbon content.

According to the FTIR spectra (Fig. 2), amount of $\mathrm{CH}_{x}$ species increased after grafting. Similar increase in $\mathrm{C}=\mathrm{O}$ species was observed in undecylenic acid functionalized samples (UnTCPSi and UnHTPSi). Increase in $=\mathrm{CH}$ species present in free undecylenic acid and decene molecules were not observed.

${ }^{29}$ Si CP-MAS NMR spectrum of TCPSi (Fig. 3) shows three prominent features. The broad resonance between -45 and +25 ppm could correspond to several species such as: (i) $\mathrm{M}_{m}$ species $\left[\mathrm{M}_{m}=\mathrm{Si}\left(\mathrm{R}, \mathrm{R}^{\prime}, \mathrm{R}^{\prime \prime}\right)(\mathrm{OH})_{1-m}(\mathrm{OSi})_{m},(0 \leq m \leq 1)\right.$ where $\mathrm{R}$, $\mathrm{R}^{\prime}$ and $\mathrm{R}^{\prime \prime}$ correspond to $\mathrm{C}$ in this particular case] that are

Table 2 Composition of the samples determined by XPS expressed as atomic \%

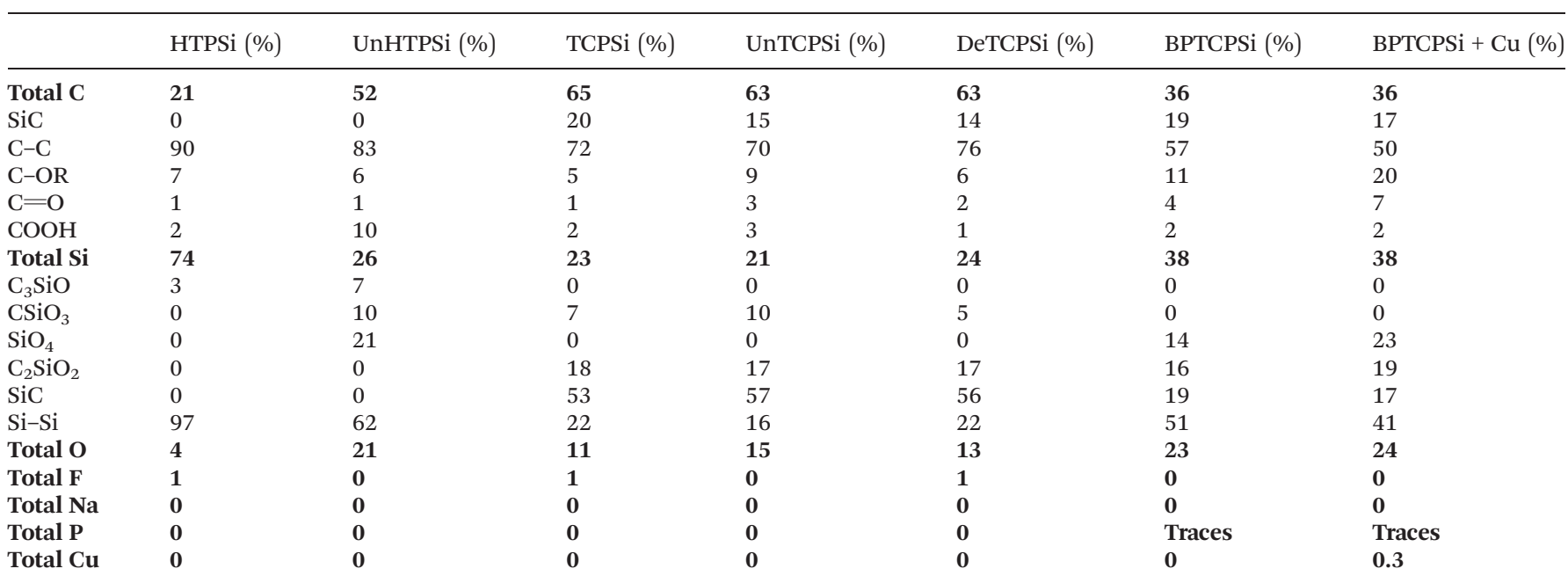




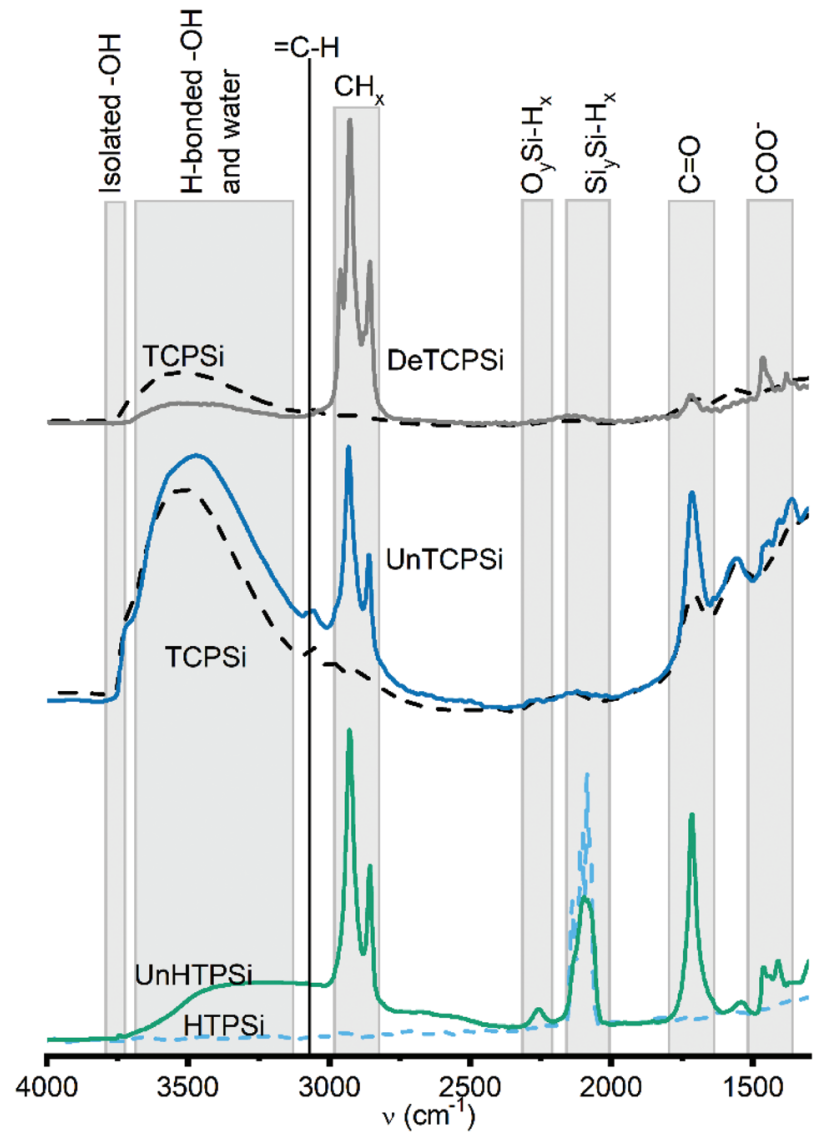

Fig. 2 FTIR spectra of functionalized (solid lines) and unfunctionalized (dashed lines) TCPSi and HTPSi samples.

expected between 0 and $15 \mathrm{ppm}$, (ii) $\mathrm{D}_{n}$ species $\left[\mathrm{D}_{n}=\left(\mathrm{R}, \mathrm{R}^{\prime}\right)\right.$-Si $\left.(\mathrm{OH})_{2-n}(\mathrm{OSi})_{n}, 0 \leq n \leq 2\right]$ expected in the -25 to $-5 \mathrm{ppm}$ range $^{27}$ and/or (iii) $\mathrm{SiC}$ (from -27 to $-10 \mathrm{ppm}$ (ref. 28)). The broad resonance may also be due to oxidized silicon species such as $\left[\mathrm{Si}(\mathrm{Si})_{n}(\mathrm{OH})_{4-n}, n=2-3\right]$ expected at -14 and $-12 \mathrm{ppm}$ or $\mathrm{Si}(\mathrm{Si})_{2}(\mathrm{OH})(\mathrm{H})$ or $\mathrm{Si}(\mathrm{Si})(\mathrm{OSi})(\mathrm{OH})(\mathrm{H})$ expected at -22 and $-24 \mathrm{ppm}$, respectively. ${ }^{29}$ These findings are supported by the XPS results in which $\mathrm{Si}-\mathrm{Si}$ groups, $\mathrm{SiC}$ species and $\mathrm{C}_{2} \mathrm{SiO}_{2}$ (D) species are the major components (see Table 2).

The broad resonance between -50 and $-80 \mathrm{ppm}$ is assigned to $\mathrm{T}_{n}$ groups $\left[\mathrm{T}_{n}=\mathrm{R}-\mathrm{Si}(\mathrm{OH})_{3-n}(\mathrm{OSi})_{n}, 0 \leq n \leq 3\right]$ such as $\mathrm{CSiO}_{3}$ species that were also detected by XPS.

The third broad resonance between -110 and $-80 \mathrm{ppm}$ could correspond to $\mathrm{Q}_{n}$ species $\left[\mathrm{Q}_{n}=\mathrm{Si}(\mathrm{OSi})_{n}(\mathrm{OH})_{4-n}, 0 \leq n \leq 4\right]$ and/or hydrogenated silicon species such as $\mathrm{O}_{3} \mathrm{SiH}$ (expected at $-84 \mathrm{ppm}), \mathrm{Si}_{3} \mathrm{SiH}(-91 \mathrm{ppm})$ and $\mathrm{Si}_{2} \mathrm{SiH}_{2}(-102 \mathrm{ppm}){ }^{30}$ Presence of $\mathrm{Q}_{n}$ species in NMR spectra despite their absence in XPS spectra can be explained by the fact that the signal corresponding to $\mathrm{Si}$ atoms spatially close to hydrogen nuclei such as SiOH species are enhanced in the ${ }^{1} \mathrm{H}^{-29} \mathrm{Si}$ CP-MAS spectrum.

Undecylenic acid and decene functionalized TCPSi show enhanced intensity of the $\mathrm{M}, \mathrm{D}$ and $\mathrm{T}$ species relative to $\mathrm{Q} /$ hydrogenated silicon species. This indicates that the surface functionalization occurs on silicon carbides/oxycarbides

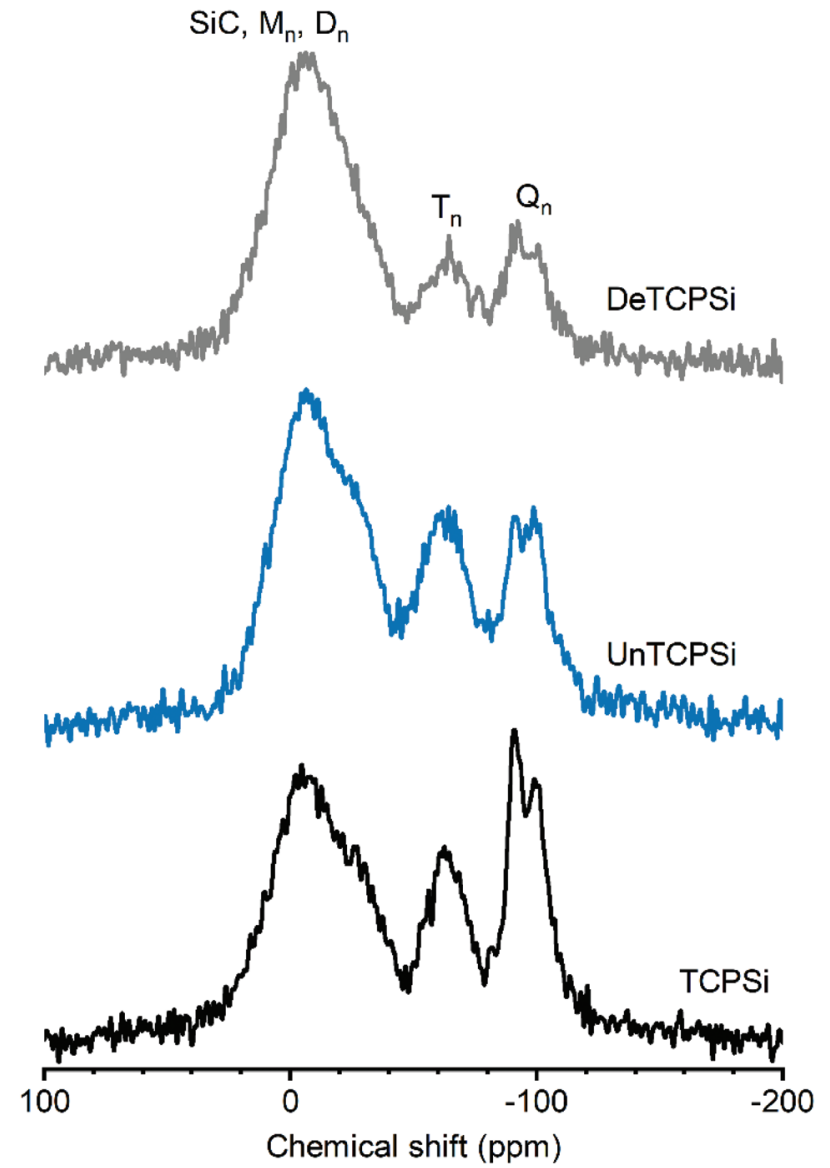

Fig. $3{ }^{29} \mathrm{Si}$ CP-MAS NMR spectra of functionalized and unfunctionalized TCPSi. The intensity of the spectra is normalized according to the height of the highest peak $\left(\mathrm{M}_{m}=\mathrm{Si}\left(\mathrm{R}, \mathrm{R}^{\prime}, \mathrm{R}^{\prime \prime}\right)(\mathrm{OH})_{1-m}(\mathrm{OSi})_{m},(0 \leq m \leq 1)\right.$; $\mathrm{D}_{n}=\left(\mathrm{R}, \mathrm{R}^{\prime}\right)-\mathrm{Si}(\mathrm{OH})_{2-n}(\mathrm{OSi})_{n}, 0 \leq n \leq 2 ; \mathrm{T}_{n}=\mathrm{R}-\mathrm{Si}(\mathrm{OH})_{3-n}(\mathrm{OSi})_{n}, 0 \leq n \leq 3$; $\left.\mathrm{Q}_{n}=\mathrm{Si}(\mathrm{OSi})_{n}(\mathrm{OH})_{4-n}, 0 \leq n \leq 4\right)$.

species because grafting of a decyl carbon chain close to $\mathrm{Si}$ atoms will enhance the magnetization transfer from ${ }^{1} \mathrm{H}$ to ${ }^{29} \mathrm{Si}$. The intensity increase is more significant for the DeTCPSi sample than for the UnTCPSi, in agreement with the higher grafting yield for DeTCPSi. The more pronounced enhancement of the resonance between -20 and $+25 \mathrm{ppm}$ with respect to the others suggests grafting of several carbon atoms on one $\mathrm{Si}$ atom is favored.

For the UnHTPSi sample, the reaction of SiH with undecyl acid creates a $\mathrm{Si}-\mathrm{C}$ bond. Indeed, resonances corresponding to $\mathrm{T}$ or D species are seen on the ${ }^{29} \mathrm{Si}$ CP-MAS NMR spectrum of UnHTPSi as expected (ESI S4 $\dagger$ ).

Measuring ${ }^{13} \mathrm{C}$ CP-MAS NMR spectra for these samples was challenging due to relatively low amount of carbon in the samples and inherently low sensitivity of the method. As reported earlier, we were able to use dynamic nuclear polarization with the endogenous radicals in the samples to obtain significantly higher quality spectra. ${ }^{12}$ Spectra of TCPSi and UnTCPSi are shown in Fig. 4. The resonance corresponding to $\mathrm{sp}^{2}$ carbon from graphitic carbon is observed in both samples between 150 and $110 \mathrm{ppm}$ (ref. 31) as well as the resonance 


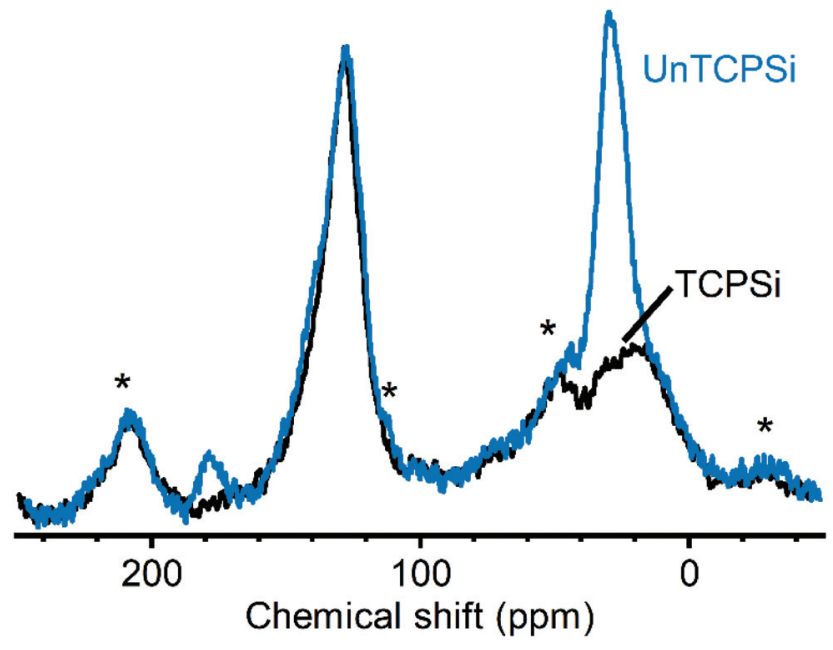

Fig. $4{ }^{13} \mathrm{C}$ CP-MAS DNP spectra of TCPSi and UnTCPSi. Spinning sidebands are marked with an asterisk.

corresponding to $\mathrm{sp}^{3}$ carbon in $\mathrm{SiC}$ and silicon oxycarbide between -10 and $40 \mathrm{ppm}^{32,33}$ As expected, UnTCPSi showed an additional resonance centered at $29 \mathrm{ppm}$ from $\mathrm{CH}_{2}$ groups and at $178 \mathrm{ppm}$ characteristic of $\mathrm{COOH}$ groups.

In order to gain insight into the grafting mechanism, EPR measurements were performed for the TCPSi samples stored under inert atmosphere before and immediately after addition of undecylenic acid. The profile fitting revealed that the spectra consisted of two Lorentzian lines with $g$-factors of $2.0034 \pm 0.0002$ and $2.0043 \pm 0.0002$ (ESI S5 $\dagger$ ). There was no statistically significant increase in the total intensity of the resonance with addition of undecylenic acid. This is not surprising since there is no obvious termination reaction for the radical addition. Interestingly, the proportional intensity of the two lines reversed after addition of undecylenic acid on the material. Before the addition of undecylenic acid, the ratio between the peak at lower and higher $g$-values was 0.09 \pm 0.02 and after the addition $1.2 \pm 0.4$. This suggests that there is a transfer of radicals from one species to another. It is challenging to identify the species definitively because of the broad resonances and disordered nature of the material. It has been shown that in $\mathrm{Si}_{x-1} \mathrm{C}_{x}$ the spins form a strongly interacting system with $g$-factors decreasing from 2.0055 to 2.0037 as $x$ increases from 0 to $1 .^{34-36}$ The low $g$-factor component corresponds likely to radicals in the parts of the material with a high carbon content and the high $g$-factor component corresponds to Si rich parts. Therefore, increase in the intensity of the lower $g$-value peak indicates increasing $\mathrm{C}$ content in Si rich parts because of the functionalization. Alternatively, the shift towards lower $g$-values may be due to transfer of radicals from Si rich parts to the organic molecule typically having $g$-factor of approximately $2.0023 .{ }^{37}$ Similar reversal in the intensities of the relative intensities of the two Lorentzian lines was not observed when undecylenic acid was added on the TCPSi which was not kept under inert conditions.

The ${ }^{29} \mathrm{Si}$ CP-MAS NMR and EPR results suggest formation of chemical bonds between the surface Si atoms and undecylenic acid molecules. However, neither of these results rule out formation of bonds between surface carbon atoms and undecylenic acid molecules. In fact, reaction with the surface carbon atoms is highly probable because carbonization of PSi results in a carbon rich surface $\mathrm{e}^{12}$ and the radical groups in the $\mathrm{SiC}$ composites are more likely to be found on carbon than silicon atoms. ${ }^{34,36}$ Furthermore, undecylenic acid molecules can react with other undecylenic molecules which have already reacted with the surface forming molecular chains. This does not seem to take place excessively because the pore size is not significantly reduced after grafting.

The main aim of the new functionalization method is to provide functionalized PSi that is stable in aqueous solutions in a wide $\mathrm{pH}$ range. To determine the stability, the UnHTPSi and UnTCPSi microparticles were immersed into $1 \mathrm{M} \mathrm{HCl}$, deionized water and $1 \mathrm{M} \mathrm{NaOH}$ at $30^{\circ} \mathrm{C}$. After $1,3,6$ and 20 days, part of the powder was collected from the liquid, washed to remove any physisorbed molecules and dried. The liquid was changed to a fresh one at each time point. Microparticles were measured with TG to determine the
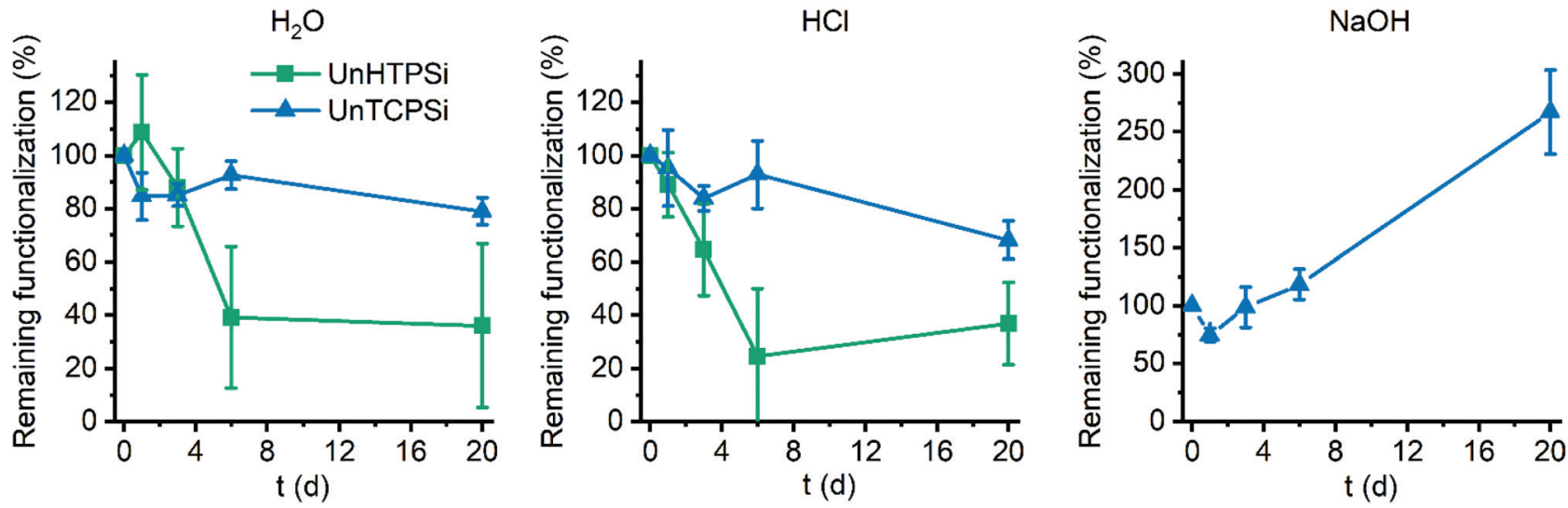

Fig. 5 Results of stability study in deionized $\mathrm{H}_{2} \mathrm{O}$ (left), $1 \mathrm{M} \mathrm{HCl}$ (middle) and $1 \mathrm{M} \mathrm{NaOH}$ (right). 


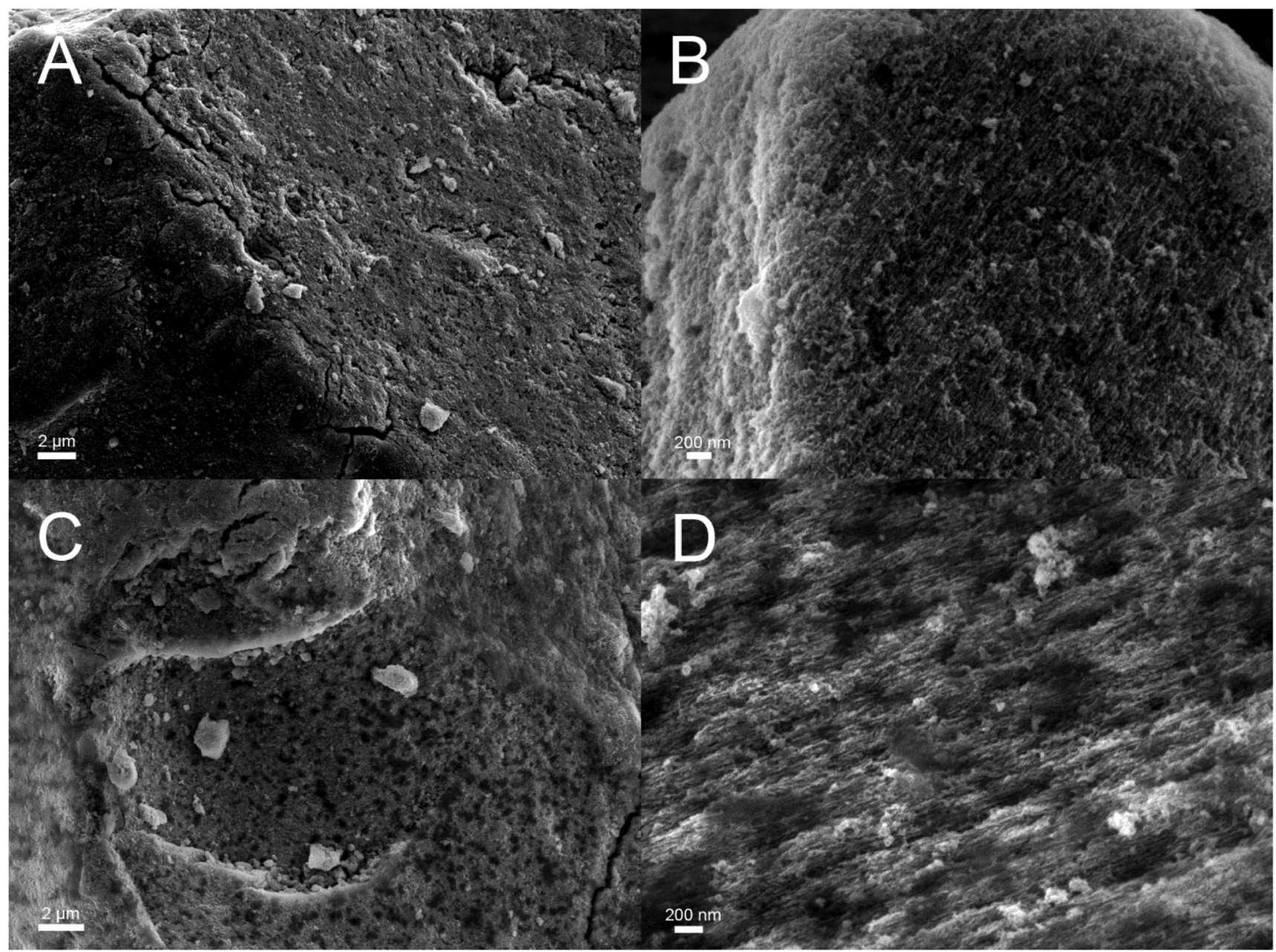

Fig. 6 Scanning electron microscopy images of UnTCPSi before (A and B) and after (C and D) 20 days incubation in $1 \mathrm{M} \mathrm{NaOH}$ solution.

amount of the remaining grafted species in the particles. The results of the stability studies (Fig. 5) show that 68 to $79 \%$ of the functional molecules in UnTCPSi remain even after 20 days in $1 \mathrm{M} \mathrm{HCl}$ and water, respectively, whereas in UnHTPSi only 24 and $39 \%$ of the molecules remains after 6 days in $1 \mathrm{M}$ $\mathrm{HCl}$ and water, respectively. In $1 \mathrm{M} \mathrm{NaOH}$ solution, UnHTPSi dissolved in just few minutes and no stability data was gathered. However, the functionalization in UnTCPSi remained relatively stable for 6 days. At $20 \mathrm{~d}$ time point, a clear increase in the amount of functionalization was observed. This counterintuitive result is due to dissolution of silicon underneath the carbonized and functionalized layer, which decreased the total mass of the sample. Because the organic layer itself was relatively stable, its mass compared to the total mass of the sample increased leading to erroneous values. This conclusion is supported by nitrogen sorption results. The surface area of UnTCPSi sample more than doubled after immersion in $1 \mathrm{M} \mathrm{NaOH}$ for 20 days indicating that dissolution of $\mathrm{Si}$ below the carbonized layer revealed new surface. The UnTCPSi samples immersed in $\mathrm{HCl}$ and water for $20 \mathrm{~d}$ showed less than $4 \%$ change in specific surface area, pore volume or average pore diameter. Pore structure of UnHTPSi sample experienced significantly larger changes. For example, the specific surface area increased 20 and $40 \%$ during $20 \mathrm{~d}$ immersion in $\mathrm{HCl}$ and water, respectively. SEM

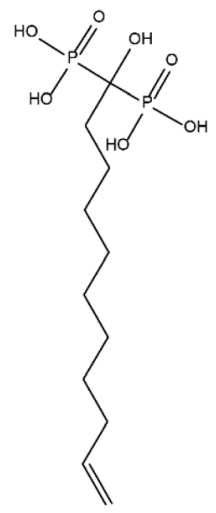

Fig. 7 Bisphosphonate molecule grafted on BPTCPSi. To prevent a reaction between the bisphosphonate group and the surface of TCPSi, the $-\mathrm{OH}$ groups were protected by replacing the hydrogen atoms with trimethylsilyl groups. The $\mathrm{OH}$ groups were deprotected by washing the BPTCPSi particles with methanol after grafting. 
images were taken of the UnTCPSi particles before and after 20 d incubation in $\mathrm{NaOH}$ (Fig. 6). The typical fir tree pore structure can still be recognized in the particles even after the 20 days incubation (Fig. 6D), but also some pits were formed in the particles (Fig. 6C and D). It can be concluded, that a highly stable surface functionalization was achieved. However, during a long immersion at very basic conditions the silicon structure under the functionalized surface begun to degrade.

The developed functionalization method was used to graft bisphosphonates (Fig. 7) on the surface of TCPSi (ESI Fig. S2 $\dagger$ ). The BPTCPSi samples contained $2.9 \pm 0.5 \mathrm{wt} \%$ of BP

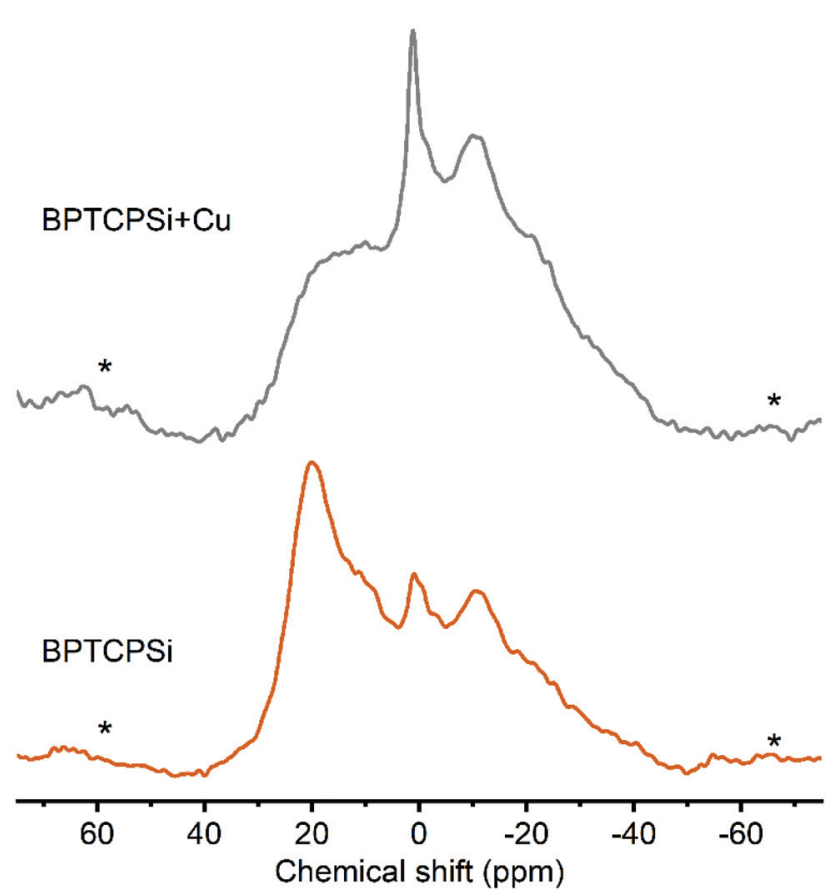

Fig. $8{ }^{31} \mathrm{P}$ MAS spectra of BPTCPSi before (bottom) and after (top) adsorption of $\mathrm{Cu}^{2+}$. The line at $20 \mathrm{ppm}$ corresponds to ${ }^{31} \mathrm{P}$ nuclei in bisphosphonates. Spinning sidebands are marked with an asterisk. molecules (Fig. 1) corresponding to coverage of 0.23 molecules per $\mathrm{nm}^{2}$. Results of the nitrogen sorption and XPS measurements are shown in Tables 1 and $2 .{ }^{29} \mathrm{Si}$ CP-MAS NMR and Fourier transform infrared spectra of the material are shown in ESI Fig. S6 and S7, $\uparrow$ respectively, and the nitrogen sorption isotherm in ESI S3. $\uparrow$ The BPTCPSi sample was characterized by ${ }^{31}$ P MAS NMR (Fig. 8). The spectrum shows an intense resonance at $20 \mathrm{ppm}$ from the phosphorus atoms of the bisphosphonate. In addition to the main resonance, decomposition of the signal suggests at least three other components at $\mathbf{- 1 1}$, 1 and 11 ppm indicating different protonation states, conformations or possible side products of the grafting reaction. ${ }^{38}$ The sharp resonance at $1 \mathrm{ppm}$ corresponds to the silylated bisphosphonate based on liquid state NMR indicating that some silyl groups that were used as protective groups during the functionalization remained in the material.

The performance of the material in metal adsorption applications was tested with $\mathrm{CuCl}_{2}$ solution. The maximum capacity of the material towards chelation of $\mathrm{Cu}^{2+}$ was $40 \pm 4 \mu \mathrm{mol} \mathrm{g}^{-1}$ corresponding to $0.46 \mathrm{Cu}^{2+}$ ions per bisphosphonate molecule. This is a slightly higher ratio than was reported for solid bisphosphonates (0.35). ${ }^{14}$ After the $\mathrm{Cu}^{2+}$ adsorption the intensity of the resonance at $20 \mathrm{ppm}$ in the ${ }^{31} \mathrm{P}$ MAS NMR spectrum decreases significantly (Fig. 7). This suggests interaction between copper and the grafted bisphosphonates as the presence of paramagnetic species such as $\mathrm{Cu}^{2+}$ is known to broaden and shift the resonances. ${ }^{39}$

The ability of the material to repeatedly adsorb copper ions from aqueous solution and subsequently to release them into $0.1 \mathrm{M} \mathrm{HCl}$ solution was tested by exposing the material to 50 consecutive adsorption-desorption cycles. Between 60 to $80 \%$ of the copper ions were adsorbed by BPTCPSi (Fig. 9). Importantly, the results show only small decrease in the performance of the material within the 50 cycles. Similar experiment was also done with unfunctionalized TCPSi. Approximately $90 \%$ of $\mathrm{Cu}^{2+}$ ions were adsorbed and $30 \%$ desorbed (relative to amount of $\mathrm{Cu}^{2+}$ ions initially in the solution) in the first cycle (Fig. 9). However, subsequent cycles showed

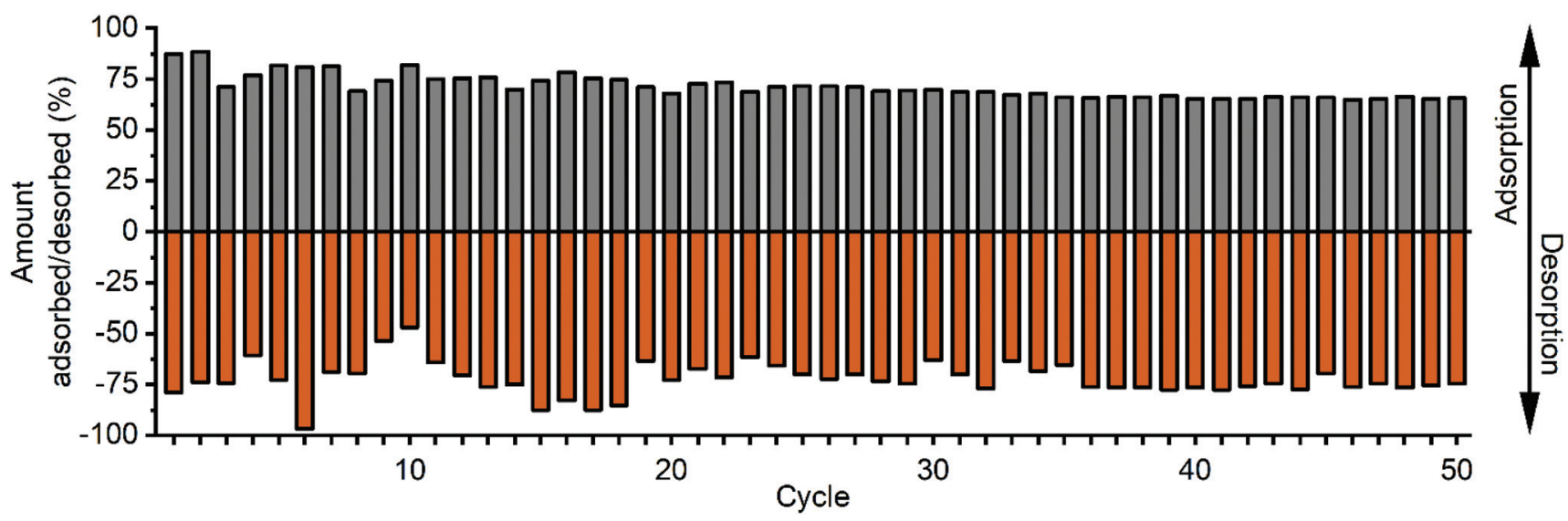

Fig. 9 Fifty adsorption-desorption cycles of $\mathrm{Cu}^{2+}$ ions on TCPSi and BPTCPSi. The amount adsorbed or desorbed is presented relative to the amount of $\mathrm{Cu}^{2+}$ available for adsorption initially. The positive values represent adsorption and negative values desorption. 
adsorption or desorption values smaller than $20 \%$. The results suggest that there is some irreversible adsorption of $\mathrm{Cu}^{2+}$ ions on TCPSi surface as well as small reversible adsorption. However, BP molecules are mainly responsible for the reversible adsorption of $\mathrm{Cu}^{2+}$ in BPTCPSi.

\section{Conclusions}

Thermally carbonized porous silicon was functionalized by grafting terminal alkenes directly on the surface. The functionalization was performed with three kinds of molecules; a linear alkane, a carboxylic acid and a bisphosphonate. The resulting material has an unprecedented stability. It can withstand immersion in aqueous solutions at low and neutral pH up to 20 days with loss of less than a third of the functionalized layer. It can also withstand highly basic solutions up to 6 days. This surface functionalization is highly beneficial in applications such as sensing and adsorption that require extended stability of the material in aqueous solutions. Applicability of the bisphosphonate functionalized material was demonstrated in metal adsorption. The material was able to adsorb and desorb copper ions from solution repeatedly for 50 cycles without significant loss of performance.

\section{Conflicts of interest}

J. R. T. N. and V.-P. L. are shareholders of 3AWater Oy which uses and has patent applications regarding the kinds of materials reported in the manuscript.

\section{Acknowledgements}

MSc. Mejor Lama's contribution to the metal adsorption experiments and MSc. Tomi Miettinen's contribution to sample preparation is acknowledged.

This work was supported by the Saastamoinen Foundation, Finnish Cultural foundation, Academy of Finland [project numbers 292601, 288531, 314552] and Tekes [HybREC project].

\section{References}

1 L. Velleman, C. J. Shearer, A. V. Ellis, D. Losic, N. H. Voelcker and J. G. Shapter, Fabrication of self-supporting porous silicon membranes and tuning transport properties by surface functionalization, Nanoscale, 2010, 2, 1756-1761.

2 K. A. Kilian, T. Böcking and J. J. Gooding, The importance of surface chemistry in mesoporous materials: Lessons from porous silicon biosensors, Chem. Commun., 2009, 2009, 630-640.

3 T. Böcking, K. A. Kilian, K. Gaus and J. J. Gooding, Modifying porous silicon with self-assembled monolayers for biomedical applications: The influence of surface coverage on stability and biomolecule coupling, Adv. Funct. Mater., 2008, 18, 3827-3833.

4 B. Sciacca, S. D. Alvarez, F. Geobaldo and M. J. Sailor, Bioconjugate functionalization of thermally carbonized porous silicon using a radical coupling reaction, Dalton Trans., 2010, 39, 10847-10853.

5 K. A. Kilian, T. Böcking, K. Gaus, M. Gal and J. J. Gooding, $\mathrm{Si}-\mathrm{C}$ linked oligo(ethylene glycol) layers in silicon-based photonic crystals: Optimization for implantable optical materials, Biomaterials, 2007, 28, 3055-3062.

6 T. Jalkanen, E. Mäkilä, T. Sakka, J. Salonen and Y. H. Ogata, Thermally promoted addition of undecylenic acid on thermally hydrocarbonized porous silicon optical reflectors, Nanoscale Res. Lett., 2012, 7, 1-7.

7 J. M. Buriak and M. J. Allen, Lewis acid mediated functionalization of porous silicon with substituted alkenes and alkynes, J. Am. Chem. Soc., 1998, 120, 1339-1340.

8 R. Boukherroub, S. Morin, D. D. M. Wayner, F. Bensebaa, G. I. Sproule, J. M. Baribeau and D. J. Lockwood, Ideal passivation of luminescent porous silicon by thermal, noncatalytic reaction with alkenes and aldehydes, Chem. Mater., 2001, 13, 2002-2011.

9 M. J. Sweetman, F. J. Harding, S. D. Graney and N. H. Voelcker, Effect of oligoethylene glycol moieties in porous silicon surface functionalisation on protein adsorption and cell attachment, Appl. Surf. Sci., 2011, 257, 67686775.

10 H. Ouyang, C. C. Striemer and P. M. Fauchet, Quantitative analysis of the sensitivity of porous silicon optical biosensors, Appl. Phys. Lett., 2006, 88, 163108.

11 J. Salonen, E. Laine and L. Niinistö, Thermal carbonization of porous silicon surface by acetylene, J. Appl. Phys., 2002, 91, 456-461.

12 J. Riikonen, S. Rigolet, C. Marichal, F. Aussenac, J. Lalevée, F. Morlet-Savary, P. Fioux, C. Dietlin, M. Bonne, B. Lebeau and V. P. Lehto, Endogenous Stable Radicals for Characterization of Thermally Carbonized Porous Silicon by Solid-State Dynamic Nuclear Polarization 13C NMR, J. Phys. Chem. C, 2015, 119, 19272-19278.

13 W. Xu, J. Riikonen, T. Nissinen, M. Suvanto, K. Rilla, B. Li, Q. Wang, F. Deng and V. P. Lehto, Amine Surface Modifications and Fluorescent Labeling of Thermally Stabilized Mesoporous Silicon Nanoparticles, J. Phys. Chem. C, 2012, 116, 22307-22314.

14 P. A. Turhanen, J. J. Vepsäläinen and S. Peräniemi, Advanced material and approach for metal ions removal from aqueous solutions, Sci. Rep., 2015, 5, 8992.

15 M. Mureseanu, A. Reiss, I. Stefanescu, E. David, V. Parvulescu, G. Renard and V. Hulea, Modified SBA-15 mesoporous silica for heavy metal ions remediation, Chemosphere, 2008, 73, 1499-1504.

16 Y. Wang, D. Liu, J. Lu and J. Huang, Enhanced adsorption of hexavalent chromium from aqueous solutions on facilely synthesized mesoporous iron-zirconium bimetal oxide, Colloids Surf., A, 2015, 481, 133-142. 
17 P. Rekha, V. Sharma and P. Mohanty, Synthesis of cyclophosphazene bridged mesoporous organosilicas for $\mathrm{CO} 2$ capture and $\mathrm{Cr}(\mathrm{VI})$ removal, Microporous Mesoporous Mater., 2016, 219, 93-102.

18 A. Muoz Garca, A. J. Hunt, V. L. Budarin, H. L. Parker, P. S. Shuttleworth, G. J. Ellis and J. H. Clark, Starch-derived carbonaceous mesoporous materials (Starbon) for the selective adsorption and recovery of critical metals, Green Chem., 2015, 17, 2146-2149.

19 Z. Wang, L. Chen, X. Du, G. Zou and X. Wang, A pillared process to construct graphitic carbon nitride based functionalized mesoporous materials, RSC Adv., 2016, 6, 1560515609.

20 L. Wang, C. Cheng, S. Tapas, J. Lei, M. Matsuoka, J. Zhang and F. Zhang, Carbon dots modified mesoporous organosilica as an adsorbent for the removal of 2,4-dichlorophenol and heavy metal ions, J. Mater. Chem. A, 2015, 3, 1335713364.

21 M. Lecouvey, I. Mallard, T. Bailly, R. Burgada and Y. Leroux, A mild and efficient one-pot synthesis of 1-hydroxymethylene-1,1-bisphosphonic acids. Preparation of new tripod ligands, Tetrahedron Lett., 2001, 42, 84758478.

22 A. B. Sieval, V. Vleeming, H. Zuilhof and E. J. R. Sudhölter, Improved method for the preparation of organic monolayers of 1-alkenes on hydrogen-terminated silicon surfaces, Langmuir, 1999, 15, 8288-8291.

23 J. Lalevée, F. Dumur, C. R. Mayer, D. Gigmes, G. Nasr, M. A. Tehfe, S. Telitel, F. Morlet-Savary, B. Graff and J. P. Fouassier, Photopolymerization of $n$-vinylcarbazole using visible-light harvesting iridium complexes as photoinitiators, Macromolecules, 2012, 45, 4134-4141.

24 M. Rosay, L. Tometich, S. Pawsey, R. Bader, R. Schauwecker, M. Blank, P. M. Borchard, S. R. Cauffman, K. L. Felch, R. T. Weber, R. J. Temkin, R. G. Griffin and W. E. Maas, Solid-state dynamic nuclear polarization at 263 GHz: Spectrometer design and experimental results, Phys. Chem. Chem. Phys., 2010, 12, 5850-5860.

25 M. Blank, P. Borchard, S. Cauffman, K. Felch, M. Rosay and L. Tometich, High-frequency CW gyrotrons for NMR/DNP applications, IEEE Int. Vac. Electron. Conf., 2012, 327-328.

26 B. M. Fung, A. K. Khitrin and K. Ermolaev, An Improved Broadband Decoupling Sequence for Liquid Crystals and Solids, J. Magn. Reson., 2000, 142, 97-101.

27 B. Alonso and C. Marichal, Solid-state NMR studies of micelle-templated mesoporous solids, Chem. Soc. Rev., 2013, 42, 3808-3820.
28 L. Gu, D. Ma, S. Yao, X. Liu, X. Han, W. Shen and X. Bao, Template-synthesized porous silicon carbide as an effective host for zeolite catalysts, Chem. - Eur. J., 2009, 15, 1344913455.

29 R. A. Faulkner, J. A. DiVerdi, Y. Yang, T. Kobayashi and G. E. Maciel, The surface of nanoparticle silicon as studied by solid-state NMR, Materials, 2013, 6, 18-46.

30 W. K. Chang, M. Y. Liao and K. K. Gleason, Characterization of porous silicon by solid-state nuclear magnetic resonance, J. Phys. Chem., 1996, 100, 1965319658.

31 C. Hontoria-Lucas, A. J. López-Peinado, J. D. D. LópezGonzález, M. L. Rojas-Cervantes and R. M. Martín-Aranda, Study of oxygen-containing groups in a series of graphite oxides: Physical and chemical characterization, Carbon, 1995, 33, 1585-1592.

32 C. T. Brigden, I. Farnan and P. R. Hania, Multi-nuclear NMR study of polytype and defect distribution in neutron irradiated silicon carbide, J. Nucl. Mater., 2014, 444, 92100.

33 S. J. Widgeon, S. Sen, G. Mera, E. Ionescu, R. Riedel and A. Navrotsky, 29Si and 13C Solid-state NMR spectroscopic study of nanometer-scale structure and mass fractal characteristics of amorphous polymer derived silicon oxycarbide ceramics, Chem. Mater., 2010, 22, 6221-6228.

34 P. J. Gaczi and D. C. Booth, ESR in CVD silicon and siliconcarbon alloys, Sol. Energy Mater., 1981, 4, 279-289.

35 T. Shimizu, M. Kumeda and Y. Kiriyama, ESR studies on sputtered amorphous SiC, SiGe and GeC films, Solid State Commun., 1981, 37, 699-703.

36 N. Ishii, M. Kumeda and T. Shimizu, A simple molecular orbital calculation of ESR g-values for amorphous Si1-xCx, Si1-xGex and Ge1-xCx, Solid State Commun., 1982, 41, 143146.

37 C. F. Young, E. H. Poindexter and G. J. Gerardi, Electron paramagnetic resonance of porous silicon: Observation and identification of conduction-band electrons, J. Appl. Phys., 1997, 81, 7468-7470.

38 M. S. Ironside, M. J. Duer, D. G. Reid and S. Byard, Bisphosphonate protonation states, conformations, and dynamics on bone mineral probed by solid-state NMR without isotope enrichment, Eur. J. Pharm. Biopharm., 2010, 76, 120-126.

39 M. Tang, K. Mao, S. Li, J. Zhuang and K. Diallo, Paramagnetic effects on the NMR spectra of isotropic bicelles with headgroup modified chelator lipids and metal ions, Phys. Chem. Chem. Phys., 2016, 18, 15524-15527. 